\title{
Perceptual factor: Quantity of food available and consummatory behavior in chickens
}

\author{
JOSEPH H. GROSSLIGHT, KENT STATE UNIVERSITY MARTIN W. SCHEIN, PENNSYLVANIA STATE UNIVERSITY \\ SHERMAN ROSS, AMERICAN PSYCHOLOGICAL ASSOCIATION SAMUEL B. LYERLY, BUREAU OF SOCIAL SCIENCE RESEARCH
}

The relationship between quantity of food available and quantity ingested was examined. Two groups of 12 chickens each were tested with feeders designed so that one type (large) visually presented more than twice the quantity of food as the other (small). The ease of obtaining the food was essentially the same for each type of feeder. No significant difference in consumption was established between the two groups, suggesting that availability of food may have been an important contaminating error in other studies.

The quantity of a stimulus available to an animal either as a reinforcer or incentive is often considered an important variable in a number of theoretical considerations in psychology. A report by Ross, Goldstein, \& Kappel (1962) described a direct relationship between the size of a pile of grain presented to a hungry chicken and the amount eaten. Their research was in part instigated by a similar finding by Katz (1937) as part of his two-component (externalinternal) determinants of a need system. The role of external stimuli or environmental factors in the development of feeding behavior in chickens has been reported by Shreck et al (1963).

However, another explanation of the Ross et al result seems possible. Ignoring contamination by the significant order effect and the small size of groups, it is possible that the smaller piles of food represent a more difficult feeding task than do the larger piles of food. Chickens tend to scatter their food and the smaller the pile the greater must be the effort required to obtain an adequate quantity of food. The larger the pile the greater will be the density of available food within a feeding area. Therefore, to more effectively test the proposed hypothesis, the ease of obtaining the food must be kept constant despite variations in the quantity of food presented.

Subjects

The Ss were 48 male Arbor Acre White Rock chicks, isolated within $48 \mathrm{hr}$. after hatching to prevent any possible effects of socialization of feeding behavior. Until 21 days of age, all birds had constant access to food and water available in kidney-shaped aluminum dishes bearing no resemblance to the test feeders. All birds were kept in light $24 \mathrm{hr}$. a day to prevent any deprivation periods that might be forced by darkness. At 20 days of age, the birds were weighed and assigned weight ranks from 1 to 48 . The 12 heaviest and 12 lightest birds were discarded at this time. The remaining 24 birds were matched for weight, and one bird from each matched pair was assigned either to large or small feeder test conditions.

\section{Apparatus}

Two feeders built of plywood (sides and bottoms) and Plexiglas (top and front) were designed to visually present different areas of food to the chicken but still maintain equal access and ease of obtaining of food on each peck (Fig. 1). Depth of the food from the opening was constant, with only the front surface side of the feeder varying. The large feeder contained 180 gm of food while the small feeder contained $75 \mathrm{gm}$. The food used was commercially available chick starter mash.

\section{Procedure}

When Ss were 16 days old, their regular feed dishes were replaced for $30 \mathrm{~min}$. by an intermediate size feeder containing $120^{1} \mathrm{gm}$ of food. This practice was repeated for the following four days giving each bird a total of 2-1/2 hr. in which to become adapted to the characteristics of the test feeders. No deprivation preceded these test periods. All Ss (48) were pre-adapted and the division into experimental and maintenance groups followed the last adaptation session.

On the 21st day of age, the experimental cycle was started. This procedure consisted of $12 \mathrm{hr}$. of food deprivation, $15 \mathrm{~min}$. of exposure to food in the test feeder, and then 23-3/4 hr. of ad lib feeding from the kidney-shaped dish. Twelve hours of food deprivation then followed reestablishing the cycle once again. The same food was employed in the test condition as was used in ad lib feeding; water was always present. This cycle was repeated 11 times. During the deprivation period care was taken to remove all traces of food from the cage surroundings and the water dishes. The very little spillage that occured during test feeding was collected and returned to the feeder in order to determine the amount consumed.
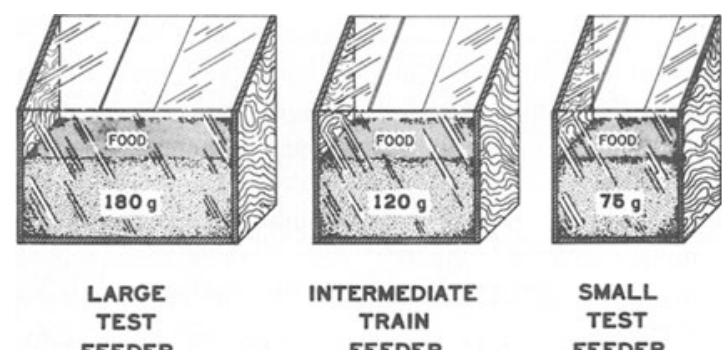

TEST

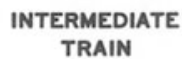

TRAIN

SMALL TEST

FEEDER

Fig. 1. Test and training feeders varying size of food pile while holding accessibility constant. 


\section{Results}

The mean amount consumed per bird for the large and small feeder groups over the 11 test trials is presented in Fig. 2. The overall analysis indicates no significant effect as a function of the size of feeder presented to the chickens. The only significant effect is that of trials $(F=5.56,10$ df., $p<.01)$. A subsequent orthogonal breakdown of the trial effect demonstrates a significant linear trend $(F=27.4,1,22 \mathrm{df}$, $\mathrm{p}<.01)$.

The difference in consumption between the large and small feeder groups is, initially, in the predicted direction; however, it fails to meet the required level

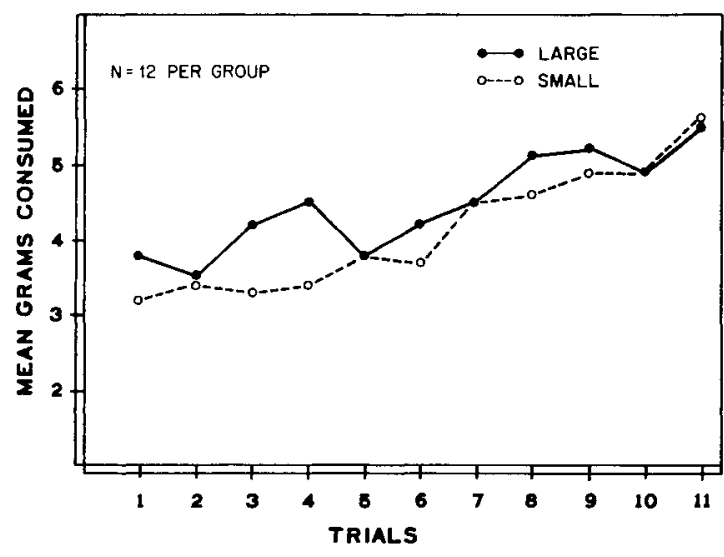

Fig. 2. Mean amount consumed for large and small feeder conditions for eleven trials. of significance. A comparison of the first trial difference $(t=1.52$ for $11 \mathrm{df})$ and the difference between the means of the first four trials $(t=1.61$ for $11 \mathrm{df})$ which, on inspection of the curves, appear to be the intervals of greatest difference, fails in test of significance. Further, the rate of change in consumption for the large feeder groups is not significantly different from the rate of change in consumption for the small feeder group. This is true (linear trend analysis) even for the first four trials where the mean differences between the two groups are largest $(F=.678)$.

\section{Discussion}

Inspection of the raw data indicates rather large variability among chickens in the quantity of food they ingest. The overlap in amount consumed in the two feeder groups is considerable. The only significant effect is the increased amount consumed over Trial 1 through 11, which is easily accounted for in terms of increased size (age) of the chicken. It would appear from this study that the significant results reported by Ross et al could be attributed to ease of eating rather than size of the stimulus.

\section{References}

Katz, D. Animals and men. London: Longmans, Green, 1937. Ross, S., Goldstein, I., \& Kappel, S. Perceptual factors in eating behavior in chicks. J. comp. physiol. Psychol., 1962, 55, 240241.

Shreck, P., Sterritt, G., Smith, M., \& Stilson, D. Environmental factors in the development of eating in chicks. Anim. Behav., $1963,11,2-3,306-309$.

\section{Note}

1. This size feeder was used based upon previous pilot study results. 